Akreditasi Ristekdikti,

No: 30/E/KPT/2019 (Sinta 4)

Paradigma,

DOI: https://doi.org/10.31294/p.v23i1.10018

Vol. 23, No. 1 Maret 2021

P-ISSN 1410-5063, E-ISSN: 2579-3500

\title{
Analisis Kesuksesan Aplikasi Jakarta Kini (JAKI) Menggunakan Model Delone And McLean
}

\author{
Dwi Andriyanto ${ }^{1}$, Fadillah Said ${ }^{2}$, Fakihotun Titiani ${ }^{3}$, Erni $^{4}$ \\ ${ }^{1}$ STMIK Nusa Mandiri \\ e-mail: 14002432@nusamandiri.ac.id \\ ${ }^{2}$ STMIK Nusa Mandiri \\ e-mail: $14002413 @$ nusamandiri.ac.id \\ ${ }^{3}$ STMIK Nusa Mandiri \\ e-mail: 14002417@nusamandiri.ac.id \\ ${ }^{4}$ STMIK Nusa Mandiri \\ e-mail:14002422@nusamandiri.ac.id
}

\begin{abstract}
Intisari - Aplikasi Jakarta Kini (JAKI) dirancang sebagai aplikasi yang dapat mewujudkan kota pintar efisien dan efektif dalam mengubah Jakarta menjadi kota metropolitan yang cerdas dan lebih baik. Tujuan dari studi ini adalah untuk mengetahui tingkat kesuksesan aplikasi jakara kini (JAKI) dan variabel mana yang paling mempengaruhi kepuasan pengguna. Penelitian ini menggunakan enam variabel dari metode DeLone and McLean yaitu: kualitas sistem, kualitas informasi, kualitas layanan, kegunaan, kepuasan pengguna, manfaat bersih. Jumlah responden yang digunakan pada penelitian ini adalah 170 responden. Hasil penelitian ini menunjukan bahwa kepuasan pengguna berpengaruh sifnifikan 59,4\% terhadap manfaat bersih. Masyarakat telah dapat merasakan manfaat Aplikasi JAKI dalam memenuhi kebutuhan warganya akan informasi terkini dan dapat mengatasi permasalahannya dengan menghemat waktu berupa pelaporan kepada pihak terkait melalui penggunaan teknologi. Sehingga penelitian ini dapat menjadi masukan bagi Pemerintah Provinsi DKI untuk memaksimalkan kegunaan Aplikasi JAKI menuju kota metropolitan yang cerdas dan interaktif.
\end{abstract}

Kata kunci: JAKI, aplikasi mobile, delone and mclean, kota pintar, pemerintah provinsi DKI.

Abstract - The Jakarta now (JAKI) application is designed as an application that can realize a smart city efficiently and effectively in turning Jakarta into a smarter and better metropolitan city. The purpose of this study is to determine the level of success of the current Jakara application (JAKI) and which variables most influence user satisfaction. This study uses six variables from the DeLone and McLean method, namely: system quality, information quality, service quality, usability, user satisfaction, net benefits. The number of respondents used in this study were 170 respondents. The results of this study indicate that user satisfaction has a significant effect of 59.4\% on net benefits. The public has been able to experience the benefits of the JAKI application in meeting the needs of its citizens for the latest information and can solve the problem by saving time in the form of reporting to related parties through the use of technology. So that this research can be an input for the DKI Provincial Government to maximize the usefulness of the JAKI Application towards a smart and interactive metropolitan city.

Keywords: JAKI, mobile application, delone and mclean, smart city, DKI provincial government

\section{PENDAHULUAN}

Jakarta Kini (JAKI) adalah aplikasi yang berisi beragam akses informasi resmi dan berbagai layanan dari pemerintah provinsi (pemprov) DKI Jakarta. Melalui JAKI pengguna aplikasi dapat mengakses informasi resmi seputar jakarta langsung dari Organisasi Perangkat Daerah (OPD) dan Badan Usaha Milik Daerah (BUMD). JAKI merupakan aplikasi berbasis kota pertama yang dikembangkan oleh Unit Pengelola Jakarta Smart City (JSC). JSC mengadaptasi konsep kota pintar melalui optimalisasi teknologi informasi komunikasi untuk mengidentifikasi, menganalisa, dan mengontrol berbagai macam data secara efisien dan efektif.

Kota pintar dianggap sebagai sebuah strategi perkotaan dengan menggunakan teknologi yang bertujuan untuk meningkatkan kualitas hidup diruang kota, sekaligus meningkatkan kualitas lingkungan dan memberikan layanan yang lebih baik kepada warganya (Benevolo, Dameri, and Auria 2016). Kota pintar telah memainkan peran kunci dalam mengubah berbagai bidang kehidupan manusia, menyentuh sektor-sektor seperti 
transportasi, kesehatan, energi, dan pendidikan (Hashem et al. 2016). Terdapat tiga jenis fokus yang berbeda terkait kota pintar: kota pintar sebagai kota yang menggunakan teknologi pintar (berfokus pada teknologi), kota pintar sebagai kota dengan orang yang pintar (berfokus pada sumber daya manusia), dan kota pintar sebagai kota dengan kolaborasi yang pintar (berfokus pada tata kelola) (Meijer and Bolívar 2016).

Salah satu model yang sering digunakan untuk mengukur kesuksesan sebuah informasi adalah Model DeLone and McLean (D \& M) (Larasati and Andayani 2019). Model D \& M dibangun berdasarkan model komunikasi Shannon dan Weaver dan dilanjutkan oleh Mason. D \& M mengukur keberhasilan Sistem Informasi berdasarkan asumsi bahwa proses dalam Sistem Informasi mirip dengan Sistem Komunikasi (Mardiana, Tjakraatmadja, and Aprianingsih 2015). Model D \& M terdiri dari 6 (enam) dimensi yang saling terkait yang harus dipertimbangkan dalam mengevaluasi Sistem Informasi yaitu Kualitas sistem, Kualitas informasi, Kualitas layanan, Penggunaan, Kepuasan Pengguna, Manfaat Bersih (Baraka, Baraka, and El-Gamily 2013).

Sebelumnya pernah dilakukan beberapa studi tentang pengaruh tingkat kesuksesan sistem menggunakan metode D\&M yang dilakukan untuk mengukur kesuksesan sistem informasi, seperti sistem learning management system (Larasati and Andayani 2019), sistem kemahasiswaan (Sapty Rahayu, Apriliyanto, and Sigit Purnomo Wuryo Putro 2018), dan sistem perhotelan (Anfina, Salisah, and Permana 2018). Penelitian-penelitian tersebut berhasil mengukur tingkat kesuksesan sebuah sistem informasi dengan baik.

Penelitian ini bertujuan melakukan analisa tingkat kesuksesan aplikasi jakarta kini (JAKI) dengan menggunakan metode delone and mclean. Dengan menggunakan enam variabel yaitu: kualitas sistem, kualitas informasi, kualitas layanan, kegunaan, kepuasan pengguna, manfaat bersih. Hal ini dilakukan, karena sebelumnya belum pernah dilakukan analisa tingkat kesuksesan pengguna pada aplikasi ini. Sehingga hasil studi ini bisa digunakan sebagai bahan pertimbangan dalam pengembangan dan menjadi masukan untuk memaksimalkan kegunaan aplikasi tersebut.

\section{METODOLOGI PENELITIAN}

Penelitian ini dilakukan untuk mengukur kesuksesan Aplikasi JAKI yang dimiliki oleh pemprov DKI Jakarta dari persepsi pengguna Aplikasi JAKI menggunakan penelitian deskriptif kuantitatif. Penentuan sampel atau responden menggunakan teknik random sampling karena pengguna aplikasi ini terdiri dari berbagai kalangan dan dilakukan secara acak tanpa memperhatikan latar belakang responden. Menggunakan teknik survei berbasis kuesioner yang digunakan sebagai instrumen pada tahap penelitian yang didistribusikan kepada responden dalam hal ini pengguna aplikasi JAKI untuk mendapatkan data primer dengan membagikan kuesioner secara online menggunakan google form. Menggunakan kuesioner berbasis model DeLone and McLean sesuai dengan standar yang ditetapkan.

Tahapan penelitian yang digunakan dalam penelitian ini dapat dibagi menjadi 4 (empat) tahap seperti terlihat pada Gambar 1, yaitu : (1) Identifikasi Masalah, (2) Penentuan Populasi dan Sampel, (3) Hasil dan Pembahasan, (4) Kesimpulan

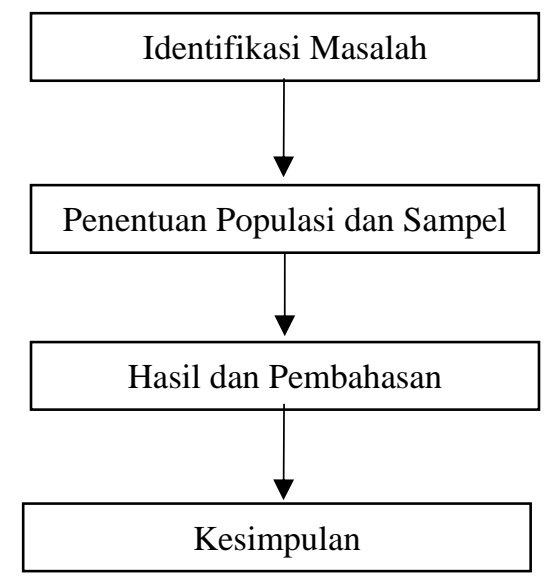

Sumber: (Andriyanto et al. 2021)

Gambar 1. Tahapan Penelitian

Model penelitian dapat dilihat pada gambar berikut:

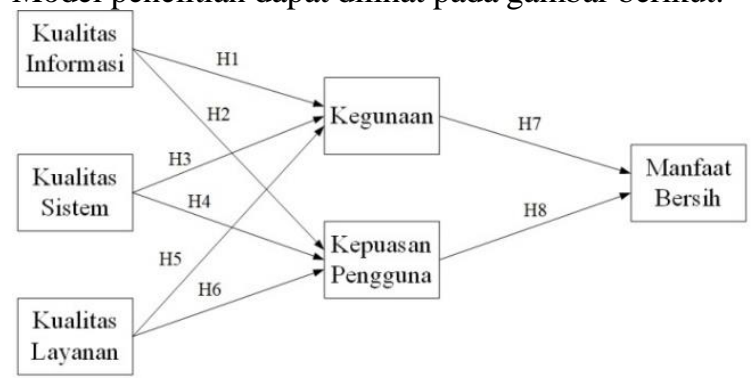

Sumber: (Andriyanto et al. 2021)

Gambar 2. Model Penelitian

Berdasarkan Gambar 2 terdapat 8 hipotesis yang akan diuji pada penelitian ini, yaitu:

H1: Kualitas Sistem berpengaruh signifikan terhadap Kegunaan

H2: Kualitas Sistem berpengaruh signifikan terhadap Kepuasan Pengguna

H3: Kualitas Informasi berpengaruh signifikan terhadap Kegunaan

H4: Kualitas Informasi berpengaruh signifikan terhadap Kepuasan Pengguna

H5: Kualitas Layanan berpengaruh signifikan 
terhadap Kegunaan

H6: Kualitas Layanan berpengaruh signifikan terhadap Kepuasan Pengguna

H7: Kegunaan berpengaruh signifikan terhadap Manfaat Bersih

H8: Kepuasan Pengguna berpengaruh signifikan terhadap Manfaat Bersih

Tabel 1. Variabel dan Indikator Penelitian model

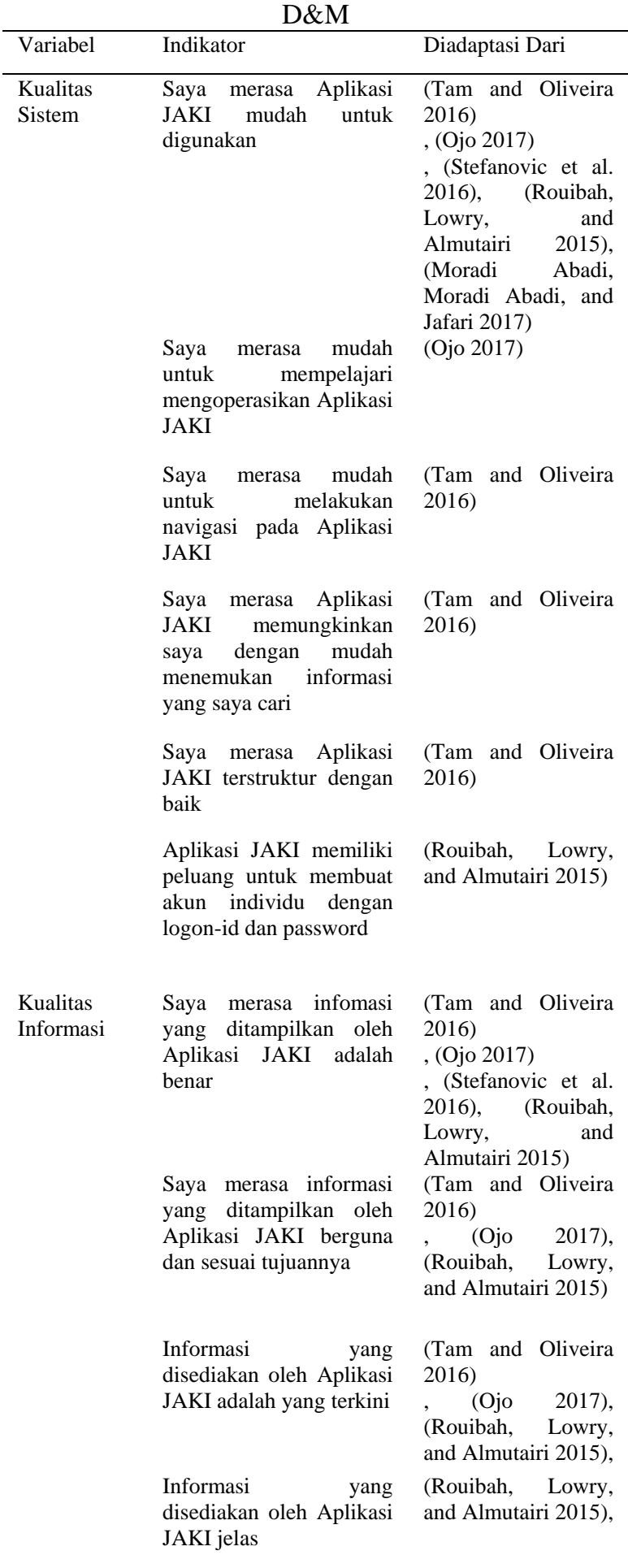

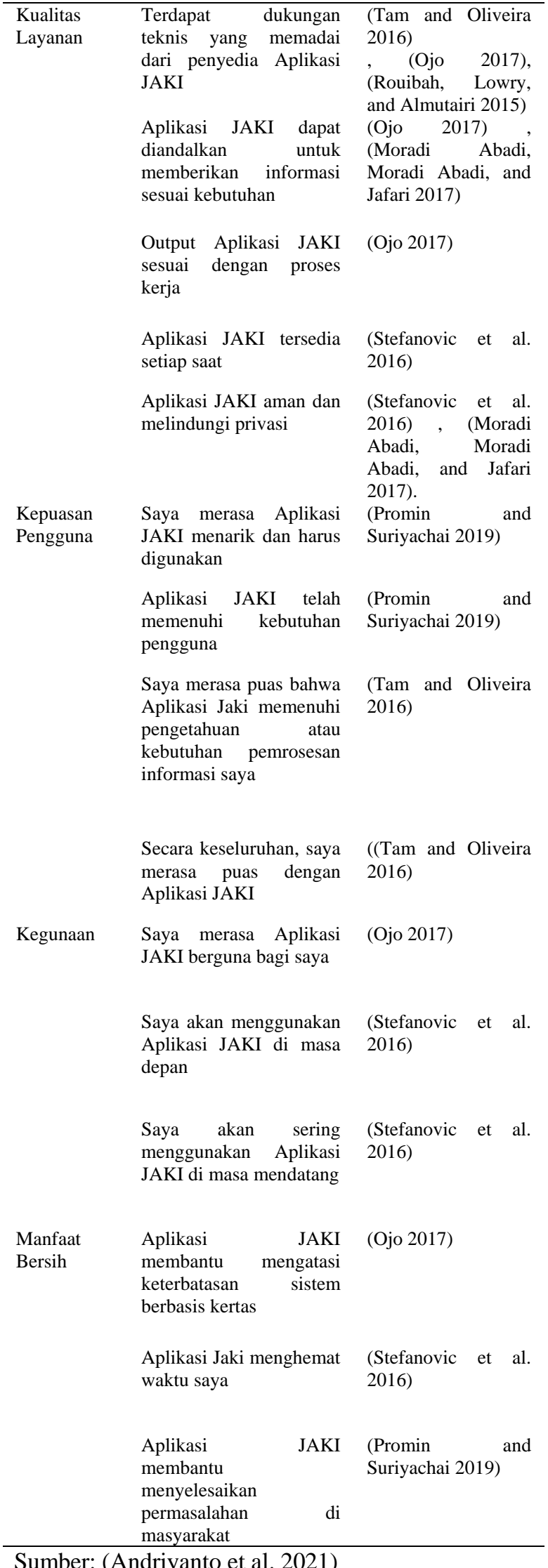

Sumber: (Andriyanto et al. 2021)

Jumlah pertanyaan yang digunakan dalam Kuesioner yang digunakan adalah 25 pertanyaan dengan 6 pertanyaan pada dimensi Kualitas Sistem, 4 
pertanyaan pada dimensi Kualitas Informasi, 5 pertanyaan pada dimensi Kualitas Layanan, 4 pertanyaan pada dimensi Kepuasan Pengguna, 3 pertanyaan pada dimensi Kegunaan, dan 3 pertanyaan pada dimensi Manfaat Bersih. Penilaian dari setiap pertanyaan menggunakan skala likert yang terdiri dari 5 pilihan jawaban untuk menilai kesuksesan aplikasi JAKI.

Tabel 2. Skala Likert

\begin{tabular}{lll}
\hline No. & Persepsi & Skor \\
\hline 1 & Sangat Tidak Setuju & 1 \\
2 & Tidak Setuju & 2 \\
3 & Netral & 3 \\
4 & Setuju & 4 \\
5 & Sangat Setuju & 5 \\
\hline
\end{tabular}

Sumber: (Andriyanto et al. 2021)

\section{HASIL DAN PEMBAHASAN}

\section{Demografi Responden}

Tabel 3. Demografi Responden

\begin{tabular}{|c|c|c|c|}
\hline \multicolumn{2}{|c|}{ Karekteristik } & \multirow{2}{*}{$\begin{array}{c}\text { Total } \\
83 \\
\end{array}$} & \multirow{2}{*}{$\begin{array}{c}\text { Persentase }(\%) \\
48.8\end{array}$} \\
\hline Jenis & Pria & & \\
\hline & Wanita & 87 & 51.2 \\
\hline \multirow[t]{5}{*}{ Umur } & $<20$ & 4 & 2.4 \\
\hline & $21-30$ & 76 & 44.7 \\
\hline & $31-40$ & 56 & 32.9 \\
\hline & $41-50$ & 28 & 16.5 \\
\hline & $>51$ & 6 & 3.5 \\
\hline \multirow[t]{5}{*}{ Pendidikan } & SMA & 4 & 2.4 \\
\hline & Diploma & 30 & 17.6 \\
\hline & Sarjana & 86 & 50.6 \\
\hline & $\begin{array}{c}\text { Pasca } \\
\text { Sarjana }\end{array}$ & 49 & 28.8 \\
\hline & Doktoral & 1 & 0.6 \\
\hline
\end{tabular}

Sumber: (Andriyanto et al. 2021)

Responden dalam penelitian ini berjumlah 170 responden yaitu masyarakat yang memiliki pengalaman menggunakan aplikasi JAKI. Berdasarkan data pada tabel 3 terdapat 83 responden berjenis kelamin pria dan 87 responden berjenis kelamin wanita. Responden berumur kurang dari 20 tahun berjumlah 4 responden, berumur 21 sampai 30 tahun berjumlah 76 responden, berumur 31 sampai 40 tahun berjumlah 56 responden, berumur 41 sampai 50 tahun berjumlah 28 responden dan lebih dari umur 51 tahun berjumlah 6 responden. Responden berdasaran pendidikannya yaitu terdapat 4 responden SMA, Diploma berjumlah 30 responden, Sarjana berjumlah 86 responden, Pasca Sarjana berjumlah 49 responden, Doktoral berjumlah 1 responden. Dalam kuesioner tersebut terdapat pertanyaan apakah responden sudah pernah menggunakan aplikasi JAKI. Pertanyaan ini digunakan untuk memastikan bahwa responden yang mengisi kuesioner adalah responden yang pernah menggunakan atau yang sering menggunakan aplikasi JAKI.

\section{Pengujian Model}

Pada tahap ini, ada tiga jenis pengujian yang dilakukan yaitu Convergence Validity, Discriminant Validity, dan Reliability Testing. Tes ini untuk melihat sejauh mana hubungan antara variabel laten dengan masing-masing indikator. Nilai Convergence Validity diambil dari outer loading setiap indikator dari setiap variabel laten. Untuk diproses lebih lanjut, nilai faktor pemuatan yang diharapkan adalah 0,7. Model penelitian dan output ditampilkan setelah hasil kuesioner diproses menggunakan Algoritma PLS dalam aplikasi SmartPLS dimana hasilnya dapat dilihat pada Tabel 4.

Tabel 4. PLS Outer Loading dan Cross Loading

\begin{tabular}{|c|c|c|c|c|c|c|c|}
\hline Construct & & $\mathrm{KS}$ & $\mathrm{KI}$ & KL & $\mathrm{K}$ & KP & $\mathrm{MB}$ \\
\hline Kualitas & KS1 & 0.88 & 0.69 & 0.73 & 0.71 & 0.70 & 0.69 \\
\hline \multirow{11}{*}{$\begin{array}{l}\text { Sistem } \\
(\mathrm{KS})\end{array}$} & & 3 & 9 & 6 & 6 & 4 & 4 \\
\hline & $\mathrm{KS} 2$ & 0.89 & 0.68 & 0.74 & 0.69 & 0.72 & 0.66 \\
\hline & & 0 & 5 & 4 & 6 & 6 & 8 \\
\hline & KS3 & 0.89 & 0.70 & 0.76 & 0.75 & 0.72 & 0.71 \\
\hline & & 7 & 7 & 5 & 9 & 8 & 5 \\
\hline & KS4 & 0.85 & 0.73 & 0.75 & 0.76 & 0.72 & 0.72 \\
\hline & & 2 & 9 & 7 & 0 & 6 & 4 \\
\hline & KS5 & 0.79 & 0.73 & 0.73 & 0.73 & 0.73 & 0.70 \\
\hline & & 1 & 3 & 8 & 6 & 5 & 9 \\
\hline & KS6 & 0.79 & 0.68 & 0.74 & 0.70 & 0.71 & 0.70 \\
\hline & & 2 & 0 & 0 & 1 & 1 & 3 \\
\hline \multirow{8}{*}{$\begin{array}{l}\text { Kualitas } \\
\text { Informas } \\
\text { i (KI) }\end{array}$} & KI1 & 0.76 & 0.90 & 0.82 & 0.82 & 0.75 & 0.71 \\
\hline & & 1 & 1 & 6 & 2 & 7 & 1 \\
\hline & $\mathrm{KI} 2$ & 0.75 & 0.89 & 0.75 & 0.74 & 0.73 & 0.67 \\
\hline & & 5 & 1 & 5 & 3 & 4 & 8 \\
\hline & $\mathrm{KI} 3$ & 0.64 & 0.86 & 0.72 & 0.67 & 0.68 & 0.61 \\
\hline & & 8 & 0 & 0 & 7 & 9 & 1 \\
\hline & KI4 & 0.78 & 0.90 & 0.83 & 0.76 & 0.79 & 0.77 \\
\hline & & 5 & 6 & 0 & 6 & 3 & 2 \\
\hline \multirow{10}{*}{$\begin{array}{l}\text { Kualitas } \\
\text { Layanan } \\
\text { (KL) }\end{array}$} & KL1 & 0.78 & 0.74 & 0.87 & 0.73 & 0.74 & 0.69 \\
\hline & & 3 & 6 & 5 & 7 & 2 & 8 \\
\hline & KL2 & 0.78 & 0.86 & 0.90 & 0.76 & 0.77 & 0.76 \\
\hline & & 4 & 4 & 2 & 5 & 5 & 1 \\
\hline & KL3 & 0.78 & 0.76 & 0.87 & 0.77 & 0.73 & 0.72 \\
\hline & & 1 & 9 & 9 & 5 & 6 & 9 \\
\hline & KL4 & 0.72 & 0.73 & 0.84 & 0.72 & 0.69 & 0.72 \\
\hline & & 8 & 4 & 0 & 7 & 9 & 7 \\
\hline & KL5 & 0.75 & 0.74 & 0.87 & 0.81 & 0.75 & 0.71 \\
\hline & & 7 & 1 & 4 & 3 & 6 & 3 \\
\hline \multirow{6}{*}{$\begin{array}{l}\text { Kegunaa } \\
\mathrm{n}(\mathrm{K})\end{array}$} & K1 & 0.81 & 0.79 & 0.79 & 0.89 & 0.78 & 0.76 \\
\hline & & 7 & 4 & 9 & 6 & 7 & 3 \\
\hline & $\mathrm{K} 2$ & 0.75 & 0.73 & 0.78 & 0.92 & 0.80 & 0.69 \\
\hline & & 6 & 9 & 1 & 2 & 6 & 4 \\
\hline & K3 & 0.77 & 0.79 & 0.82 & 0.93 & 0.81 & 0.77 \\
\hline & & 8 & 4 & 1 & 1 & 7 & 2 \\
\hline \multirow{8}{*}{$\begin{array}{l}\text { Kepuasa } \\
\mathrm{n} \\
\text { Penggun } \\
\text { a (KP) }\end{array}$} & KP1 & 0.76 & 0.76 & 0.77 & 0.81 & 0.89 & 0.82 \\
\hline & & 4 & 5 & 9 & 4 & 2 & 6 \\
\hline & KP2 & 0.74 & 0.73 & 0.74 & 0.78 & 0.92 & 0.77 \\
\hline & & 3 & 7 & 8 & 8 & 0 & 7 \\
\hline & KP3 & 0.78 & 0.75 & 0.75 & 0.77 & 0.91 & 0.73 \\
\hline & & 1 & 1 & 9 & 1 & 3 & 3 \\
\hline & KP4 & 0.78 & 0.78 & 0.79 & 0.80 & 0.90 & 0.75 \\
\hline & & 9 & 2 & 4 & 6 & 4 & 1 \\
\hline \multirow{6}{*}{$\begin{array}{l}\text { Manfaat } \\
\text { Bersih } \\
(\mathrm{MB})\end{array}$} & MB1 & 0.70 & 0.64 & 0.70 & 0.66 & 0.71 & 0.88 \\
\hline & & 9 & 5 & 4 & 2 & 5 & 4 \\
\hline & MB2 & 0.75 & 0.70 & 0.72 & 0.72 & 0.75 & 0.91 \\
\hline & & 4 & 0 & 9 & 2 & 8 & 5 \\
\hline & MB3 & 0.73 & 0.73 & 0.77 & 0.77 & 0.79 & 0.86 \\
\hline & & 4 & 2 & 3 & 2 & 1 & 6 \\
\hline
\end{tabular}




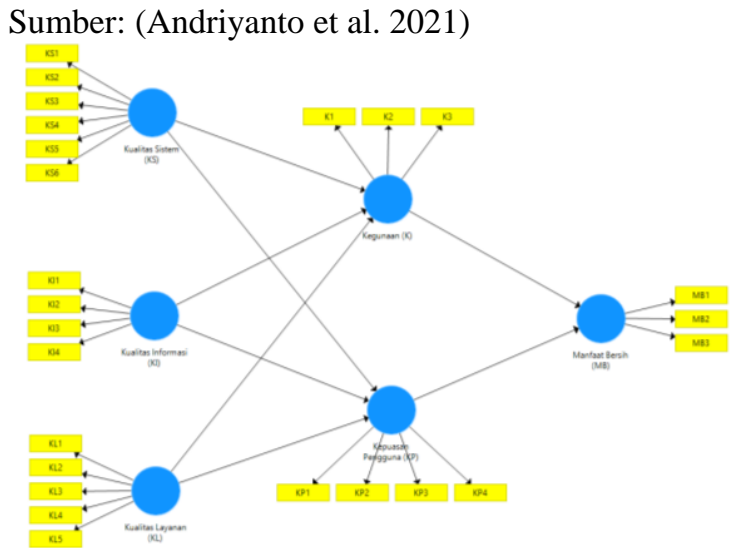

Sumber: (Andriyanto et al. 2021)

Gambar 3. Diagram SmartPLS

Berdasarkan persepsi pengguna dari masing-masing indikator, memiliki nilai outer loading lebih dari 0,7. Ini berarti memiliki dampak positif pada kesuksesan Aplikasi JAKI. Konstruk akan valid dan dapat diandalkan jika memiliki nilai AVE di atas 0,50, reliabilitas komposit di atas 0,70 dan nilai alfa Cronbach di atas 0,70 (Thung, F, 2019). Tabel 5 menunjukkan bahwa hal ini memenuhi persyaratan, sehingga akan sama bahwa model penelitian yang dilakukan mengandung hasil positif.

\begin{tabular}{llll}
\multicolumn{4}{c}{ Tabel 5. Valititas Konvergen } \\
\hline Variable & $\begin{array}{c}\text { Cronbach } \\
\text { Alpha }\end{array}$ & $\begin{array}{l}\text { Composite } \\
\text { Reliability }\end{array}$ & AVE \\
\hline KS & 0.924 & 0.941 & 0.726 \\
KI & 0.912 & 0.938 & 0.792 \\
KL & 0.923 & 0.942 & 0.764 \\
K & 0.905 & 0.940 & 0.840 \\
KP & 0.928 & 0.949 & 0.823 \\
MB & 0.866 & 0.918 & 0.789 \\
\hline
\end{tabular}

Sumber: (Andriyanto et al. 2021)

Nilai koefisien determinasi $\left(\mathrm{R}^{2}\right)$ menunjukkan besarnya pengaruh antar variable laten. Hasil uji nilai koefisien korelasi dapat dilihat pada Tabel 6.

\begin{tabular}{|c|c|c|}
\hline Variable & Nilai $R^{2}$ & Keterangan \\
\hline $\mathrm{K}$ & 0.813 & Kuat \\
\hline KP & 0.786 & Kuat \\
\hline MB & 0.744 & Kuat \\
\hline
\end{tabular}

Sumber: (Andriyanto et al. 2021)

Hipotesis dapat diterima jika nilai T-Statistic lebih besar dari 1,64 dan jika terjadi sebaliknya, hipotesis tidak diterima. Seperti yang ditunjukkan pada tabel 7 terlihat bahwa tes yang dilakukan dengan menggunakan SmartPLS nilai T-Statistik memiliki nilai lebih besar dari 1,64 sehingga Hipotesis $1(\mathrm{H} 1)$ sampai dengan Hipotesis 8 (H8) diterima.

Tabel 7. Hasil Tes Hipotesis

\begin{tabular}{ccccc}
\hline Hipotesis & $\begin{array}{c}\text { Mean } \\
(\mathrm{M})\end{array}$ & $\begin{array}{c}\text { Standard } \\
\text { Deviation } \\
(\text { STDEV })\end{array}$ & $\begin{array}{c}\text { T Statistic } \\
(|\mathrm{O} / \mathrm{STDEV}|)\end{array}$ & Hasil \\
\hline KS->K & 0.323 & 0.100 & 3.225 & Diterima \\
$\mathrm{KS}->\mathrm{KP}$ & 0.378 & 0.097 & 3.858 & Diterima \\
$\mathrm{KI}->\mathrm{K}$ & 0.262 & 0.093 & 2.810 & Diterima \\
$\mathrm{KI}->\mathrm{KP}$ & 0.295 & 0.118 & 2.545 & Diterima \\
$\mathrm{KL}->\mathrm{K}$ & 0.360 & 0.131 & 2.757 & Diterima \\
$\mathrm{KL}->\mathrm{KP}$ & 0.256 & 0.127 & 2.032 & Diterima \\
$\mathrm{K}->\mathrm{MB}$ & 0.294 & 0.108 & 2.630 & Diterima \\
KP->MB & 0.594 & 0.105 & 5.737 & Diterima \\
\hline Sumbe
\end{tabular}

Sumber: (Andriyanto et al. 2021)

\section{KESIMPULAN}

JAKI dapat dikategorikan sebagai aplikasi yang baik dengan hasil pengaruh dari enam dimensi kesuksesan model Delone and McLean. Responden menunjukkan respon yang signifikan dalam penggunaan kualitas sistem Aplikasi JAKI terhadap kegunaan maupun kepuasan yang diperoleh pengguna, seperti kemudahan dalam mengoperasikan, menemukan informasi serta kemudahan penjelajahan menu yang diakses. Kualitas Informasi berpengaruh signifikan terhadap Kegunaan dan Kepuasan Pengguna sehingga pengguna meyakini informasi yang didapatkan adalah benar, jelas dan terkini. Adanya dukungan teknis yang memadai serta ketersedian layanan setiap saat telah dapat menunjukkan Kualitas Layanan berpengaruh signifikan terhadap kepuasan pengguna dan kegunaan. Dengan adanya Aplikasi JAKI membantu masyarakat dalam mengatasi permasalahannya melalui sistem berupa pelaporan kepada pihak terkait tanpa menggunakan kertas serta menghemat waktu sehingga memiliki pengaruh kepuasan pengguna dan kegunaan terhadap manfaat bersih sebesar $59,4 \%$.

Penelitian ini memberikan rekomendasi kepada Pemerintah Provinsi (Pemprov) DKI Jakarta untuk tetap menggunakan aplikasi JAKI sebagai media interaktif dalam melayani kebutuhan warganya dalam mendapatkan informasi yang resmi, terkini, efektif, efisien menuju kota metropolitan yang cerdas dan lebih baik.

\section{REFERENSI}

Andriyanto, Dwi, Fadillah Said, Fakihotun Titiani, and Erni Erni. 2021. "Analisis Kesuksesan Aplikasi Jakarta Kini (Jaki) Menggunakan Model Delone And Mclean."

Anfina, Anggiana, Febi Nur Salisah, and Inggih Permana. 2018. "Analisa Kesuksesan Penerapan Sistem Perhotelan Dengan Pendekatan Model Delone and Mclean." Jurnal Ilmiah Rekayasa dan Manajemen Sistem Informasi 4(1): 56-59. 
Baraka, Hesham A., Hoda A. Baraka, and Islam H. El-Gamily. 2013. "Assessing Call Centers' Success: A Validation of the DeLone and Mclean Model for Information System." Egyptian Informatics Journal 14(2): 99-108. http://dx.doi.org/10.1016/j.eij.2013.03.001.

Benevolo, Clara, Renata Paola Dameri, and Beatrice D Auria. 2016. "Empowering Organizations: Enabling Platforms and Artefacts." 11: 315. http://link.springer.com/10.1007/978-3-31923784-8.

Hashem, Ibrahim Abaker Targio et al. 2016. "The Role of Big Data in Smart City." International Journal of Information Management 36(5): 748-58. http://dx.doi.org/10.1016/j.ijinfomgt.2016.05.0 02.

Larasati, Niken Ayu, and Sri Andayani. 2019. "Pengaruh Penggunaan Learning Management System ( LMS ) Terhadap Tingkat Kepuasan Mahasiswa Menggunakan Metode DeLone and McLean." 04: 13-20.

Mardiana, Siti, Jann H. Tjakraatmadja, and Atik Aprianingsih. 2015. "DeLone-Mclean Information System Success Model Revisited: The Separation of Intention to Use - Use and the Integration of Technology Acceptance Models." International Journal of Economics and Financial Issues 5(July 2016): 172-82.

Meijer, Albert, and Manuel Pedro Rodríguez Bolívar. 2016. "Governing the Smart City: A Review of the Literature on Smart Urban Governance." International Review of Administrative Sciences 82(2): 392-408.

Moradi Abadi, Amitis, Artonis Moradi Abadi, and Abbas Jafari. 2017. "Innovation Acceptance and Customer Satisfaction. A Survey on Tax Information Systems." AD-minister (june): 149-71.

Ojo, Adebowale I. 2017. "Validation of the Delone and Mclean Information Systems Success Model." Healthcare Informatics Research 23(1): 60-66.

Promin, Ekkapong, and Petcharat Suriyachai. 2019. "Improvement of Scanned Medical Document Management System." $2019 \quad$ 11th International Conference on Knowledge and Smart Technology, KST 2019: 126-31.

Rouibah, Kamel, Paul Benjamin Lowry, and Laila Almutairi. 2015. "Dimensions of Business-toConsumer (B2C) Systems Success in Kuwait:
Testing a Modified DeLone and McLean IS Success Model in an e-Commerce Context." Journal of Global Information Management 23(3): 41-71.

Sapty Rahayu, Flourensia, Robert Apriliyanto, and Yohanes Sigit Purnomo Wuryo Putro. 2018. "Analisis Kesuksesan Sistem Informasi Kemahasiswaan (SIKMA) Dengan Pendekatan Model DeLone Dan McLean." Indonesian Journal of Information Systems 1(1): 34-46.

Stefanovic, Darko et al. 2016. "Assessing the Success of E-Government Systems: An Employee Perspective." Information and Management 53(6): 717-26.

Tam, Carlos, and Tiago Oliveira. 2016. "Understanding the Impact of M-Banking on Individual Performance: DeLone \& McLean and TTF Perspective." Computers in Human Behavior 61: 233-44. http://dx.doi.org/10.1016/j.chb.2016.03.016.

Thung, Feby. 2019. "Pengaruh Kualitas Pelayanan Mitra Go-Jek Terhadap Loyalitas Pelanggan Dengan Kepuasan Sebagai Variabel Mediasi." Jurnal Bina Manajemen 8 No.1: 74-95.

\section{PROFIL PENULIS}

Dwi Andriyanto, S.Mn. Tahun 2008 lulus dari Program Strata Satu (S1) Program Studi Manajemen Universitas Terbuka. Saat ini bekerja sebagai Pranata Komputer Ahli Muda di Direktorat Jenderal Pajak, Direktorat Teknologi Informasi dan Keuangan (TIK)

Fadillah Said, S.Kom. Tahun 2010 lulus dari Program Strata Satu (S1) Program Studi Sistem Informasi STMIK Nusa Mandiri. Saat ini bekerja sebagai Pranata Komputer Ahli Pertama di Badan Penelitian dan Pengembangan Hukum dan Hak Asasi Manusia.

Fakihotun Titiani, S.Kom. Tahun 2020 lulus dari Program Strata Satu (S1) Program Studi Teknik Informatika STMIK Nusa Mandiri. Saat ini sedang melanjutkan kuliah pada Program Pasca Sarjana (S2) Program Studi Ilmu Komputer di STMIK Nusa Mandiri.

Erni, S.Kom. Tahun 2020 lulus dari Program Strata Satu (S1) Program Studi Sistem Informasi STMIK Nusa Mandiri. Saat ini sedang melanjutkan kuliah pada Program Pasca Sarjana (S2) Program Studi Ilmu Komputer di STMIK Nusa Mandiri. 